\title{
An Investigation of Learners' Writing Self-Efficacy and Risk Taking in Writing
}

\author{
Faradina Primarini Noorhaya Sari
}

Master of English Education, University of Lampung, Indonesia

\begin{abstract}
This study was a quantitative research conducted to find out the correlation between writing self-efficacy and writing. Additionally, this study also aimed to find the correlation between risk taking and writing. The subjects of this study were first grade students of vocational school. The instruments were writing selfefficacy questionnaire, writing risk taking questionnaire, and writing test. To analyse the data for both objectives, Spearman rho was used. The result showed firstly that there was not any significant correlation between writing self-efficacy and writing. Secondly, it was identified that there was not any significant correlation between writing risk taking and writing.
\end{abstract}

Keywords: writing self-efficacy, writing risk taking, and writing

\section{INTRODUCTION}

Affective domain is considered as one of factors that hinders or facilitates language acquisition. It is recognized as having some relevance for language learning where it is the emotional side or feeling of human behavior and learning achievement greatly is influenced by this feature or depends on how people feel about themselves. It is relevant with Hui Ni (2012) that affective variable is defined as the area of emotion and feeling which at the same time it can contribute or inhibit language learning achievement. In second language acquisition, every learner has a set of cognitive and affective states but the weight and outcome that result from the interaction between these states and other factors may differ significantly.

For many psychologists, personality traits make a difference in how people perform and what they learn. Richards and Schmidt (2002) defined personality as those aspects of an individual's behavior, attitude, beliefs, thoughts, actions and feelings which are seen as typical and distinctive of that person and recognized as such by that person and others. Personality traits are considered as an important element of individual differences since every individual is frequently judged depending on his or her personality. Wright and Taylor as cited in Zafar and Meenakshi (2012) state that personality refers to those relatively stable and enduring aspects of the individual which distinguish him from other people, and at the same time, form the basis of our predictions concerning his future behavior. In short, individual's personalities distinguish a person from others.

A number of personality traits have been identified such as self-efficacy (Bandura, 1997) and risk-taking (Ely, 1986) and they are assumed as predicating variables of success in second language acquisition. In this case, self-efficacy for academic achievement exert a notable influence on learning, grades, and career choices as they sustain effort, persistence, and aspirations (Caprara et al, 2011). It was introduced by Bandura (1997) as belief in one's capabilities to organize and execute the courses of action required to produce given attainment. Self-efficacy is one of personality traits that contributes or impedes success in second language acquisition since 
it influences the courses of action learners choose to pursue during the task. Many researchers have shown that self-efficacy predicts learners' achievement and affects the primary decision to take on an action, the amount of perseverance shown, and the capability to control affective influences during the task. As stated by Bandura in Yusuf (2011) self-efficacy stressed that human action and success depend on how deep the interactions between one's personal thoughts and given task.

In relation to self-efficacy, there are several previous studies that have been done by Rahimi and Abedini (2009), Lee and Reid (2016), and Leeming (2017). They pointed out that the achievement of language skills differed significantly across the learners with high self-efficacy and those with low self-efficacy. Learners' with high self-efficacy performed better in language skills and tasks assigned to them rather than those with low self-efficacy. In short, self-efficacy perhaps is a strong predictor of achievement in different language skills and tasks.

Another personality trait that has been assumed as a predictor variable of success in second language acquisition is risk taking. Risk-taking is identified as one of the important characteristics of successful learning in a second or foreign language (Brown, 2000). It is viewed as willingness to make a decision something new and different without putting the primary focus on success or failure (Bem as cited in Youngjoo, 1999). Learners have to be able to gamble a bit, to be willing to try hunches about the language and take the risk of being wrong in performing several tasks. It should be done by the learners since learning is the reward for taking risks. In line with the statement before, according to Youngjoo (1999) there is the risk of making mistakes and probability of loss or failure however there is the gain of learning through trial, mistake, or error.

In terms of language skills and second language acquisition, most of the literature regarding risk taking has focused on speaking skill and it has been explored by some researcher namely Tavakoli and Ghoorchaei (2009), Wang and Lin (2015), and Suryani and Argawati (2018). Much research there examined risk-taking in oral performance in EFL classroom and it is identified that high risk-taker or risk taker tends to achieve better result in language learning and being a risk taker leads learners to develop communicative competence. Additionally, risk-taking students have more access to comprehensible input, which is a key element for the successful acquisition of a second language.

Regarding language skills, writing is one of four language skills and it is identified as a productive skill whose goal is to assist learners in expressing their idea in written form. It is a fundamental importance to learning, to development of the person in each learner, and to success in the educational system. As a result, writing has become a main basis upon that ones learning, ones work, and one intellect will be judged in university, in community, and in the workplace (Khalifa, 2016).

Writing has largely attracted the attention of researchers as being a crucial skill that contributes in learning any language. Hence, writing itself is a process of thinking to invent ideas, thinking how to express the ideas into good writing and thinking how to arrange it all into paragraphs properly and clearly (Nunan, 1991). Nonetheless, as learners learn to write inside or outside the classroom settings, they encounter difficulties which hinder their writing proficiency. The writing difficulties are commonly shared among English native speakers, and even students who are learning English both as a second or foreign language (Aragón, Baires \& Rodriguez, 2013). This issue may be traced back to the components of a good piece of writing (Raimes, 1983) which students need to take into account while composing in English.

Learners' writing achievement is often influenced by their personality traits since it might tend to be volatile, affecting 
not only overall progress but responses to particular learning activities on a day-by day and even moment-by-moment basis (Geramian et al, 2012). According to Zafar et al (2012), personality traits can be facilitative or debilitative. In other words, it might contribute to academic achievement in some situation; however, personality traits might impair achievement. Precisely, self-efficacy and risk taking are personality traits that have been found important in predicting educational success.

Regarding self-efficacy, in school, for example, the beliefs that learners develop about their academic capabilities help determining what they do with the knowledge and skills they possess. Consequently, other influences on their academic achievements are in large part the result of what learners actually believe they can accomplish. This is relevant with Pajares and Valiante (1997) that selfefficacy beliefs affect what learners do by influencing the choices they make, the effort they expend, the persistence and perseverance they exert in the face of adversity, and the anxiety they experience. In relation to writing, believing that learners are capable writers it might create interest in writing, more sustained effort, and perseverance and resiliency when obstacles get in the way of the task. Thus, it is assumed when learners believe in their capabilities to write, they will feel less apprehensive about writing the task. The eventual success that learners achieve in a writing task is at least partially a factor of their belief that they indeed are fully capable of accomplishing the task.

Meanwhile, risk-taking is also shown to be related to success in language learning and according to Rubin in Samaranayake (2015) good language learners are supposed to be risk-takers. They are willing to guess, willing to appear foolish, to be risk-takers and willing to try out new structures about which they are unsure. Brown (2000) also claims that learners have to be able to gamble a bit, to be willing to try out hunches of the language and take the risk of being wrong. Besides, learning is the reward of taking risks. On top of that, this current study assumes that in writing, it involves risk taking and this assumption is based on some statement from Khalifa (2016). Writing helps students to communicate, learn, and express. When the students write, they have the opportunity to be adventurous with the language, to go beyond what they have just to say, and to take risks. In short, writing is a process in which the students have some chance to venture with the language, to convey the ideas better than what they can say orally, and to take risks of being wrong in using the language. Thus, it can be assumed that writing involves risk taking since it is not merely putting down word to form a sentence, it provides opportunity for the students to try new language and take risk of being wrong.

In accordance to the explanation above, the author is mainly interested in investigating the correlation between writing self-efficacy and risk taking towards writing. Some research questions are formulated as follows:

1. Is there any significant correlation between writing self-efficacy and writing?

2. Is there any significant correlation between writing risk taking and writing?

\section{METHODS}

This research was a quantitative research and relied on the correlation between self-efficacy and risk taking towards writing. To conduct the research, the researcher used a co-relational design of ex post facto designs (Hatch and Farhady, 1982). Ex post facto design was used in this research since there was no treatment on the subject. It involved only one group and does not use control class. This design is often called co-relational study.

In determining the sample, this research used random sampling so that those all the first year classes got the same chance to be the sample and this research used three classes as the sample of the research. The 
total numbers of participants in this research were fifty seven. This research used writing self-efficacy questionnaire, writing risk taking questionnaire, and writing test as the instrument. Writing self-efficacy questionnaire that was used in this study was adapted from Hetthong and Teo (2013), Chea and Sumow (2014), Khojasteh et al (2016), and Latif (2007). Meanwhile, writing risk taking questionnaire was adapted and developed based on Ely (1986), Mclain (1993), and Luft (2007). Each questionnaire consisted of 21 items and had be tested before for validity and reliability. Reliability of writing self-efficacy questionnaire was 0.779 and for the writing risk taking questionnaire was 0.858. Both questionnaires also were identified as a valid instrument. In analyzing the data, Spearman rho was used to identify the correlation.

\section{RESULTS}

As table 1 illustrates, the coefficient correlation or $r_{s}$ value between self-efficacy and writing is .130 . Thus, it can be said that there is a weak magnitude of correlation between self-efficacy and writing. Additionally, the not working hypothesis $\left(\mathrm{H}_{0}\right)$ is rejected if the significant level is higher than 0.05. Meanwhile, the working hypothesis $\left(\mathrm{H}_{1}\right)$ is accepted if the significance level is lower than 0.05 . Referring to the table, the significance level value for self-efficacy and writing is higher than 0.05. It means that the working hypothesis $\left(\mathrm{H}_{1}\right)$ is rejected. It can be concluded that there is not any significant correlation between self-efficacy and writing.

Table 1 Correlation Test

\begin{tabular}{|l|l|l|l|l|}
\hline Correlation & & & SE & Writing \\
\hline \multirow{4}{*}{ Spearman's rho } & SE & Correlation Coefficient & 1.000 & .130 \\
\cline { 2 - 5 } & & Sig. (2-tailed) &. & .335 \\
\cline { 2 - 5 } & & N & 57 & 57 \\
\cline { 2 - 5 } & Writing & Correlation Coefficient & .130 & 1.000 \\
\cline { 2 - 5 } & & Sig. (2-tailed) & .335 &. \\
\cline { 2 - 5 } & & N & 57 & 57 \\
\hline
\end{tabular}

On the other hand, the following table shows the correlation result between writing risk taking and writing.

Table 2 Correlation Test

\begin{tabular}{|l|l|l|l|l|}
\hline Correlation & \multicolumn{5}{|c|}{} \\
\hline \multirow{3}{*}{ Spearman's rho } & RT & Correlation Coefficient & 1.000 & .112 \\
\cline { 2 - 5 } & & Sig. (2-tailed) &. & .406 \\
\cline { 2 - 5 } & & N & 57 & 57 \\
\cline { 2 - 5 } & Writing & Correlation Coefficient & .112 & 1.000 \\
\cline { 2 - 5 } & & Sig. (2-tailed) & .406 &. \\
\cline { 2 - 5 } & & N & 57 & 57 \\
\hline
\end{tabular}

The coefficient correlation $r_{s}$ Value between risk taking and writing is .112. This calculation denotes that there is a weak magnitude of correlation between risk taking and writing. In addition, the not working hypothesis $\left(\mathrm{H}_{0}\right)$ is rejected if the significant level is higher than 0.05 . On the other hand, the working hypothesis $\left(\mathrm{H}_{1}\right)$ is accepted if the significance level is lower than 0.05. According to the table above, the significance level value for risk taking and writing is higher than 0.05 . It means that the working hypothesis $\left(\mathrm{H}_{1}\right)$ is rejected. It can be said that there is not any significant correlation between risk taking and writing.

\section{DISCUSSIONS}

a) Correlation between Writing SelfEfficacy and Writing

The reason why there is no correlation between writing self-efficacy and writing since there is no direct 
relationship between writing self-efficacy and writing. It is assumed that there is another factor which might directly affect writing.

Considering self-efficacy, this result is contrary to the previous researches that indicated that writing self-efficacy and writing had significant correlation (Chea,and Shumow, 2014 and Hetthong et al, 2013). Those previous researches found that self-efficacy had the strongest predicting power over writing and maintain the claim made by Bandura (1986), that self-efficacy behaves as an essential function in predicting writing performance. Conversely, the finding from this study supports previous researches (Hashemnejad et al, 2014 and Khojasteh et al, 2016) that identifies that there is no correlation between writing self-efficacy and writing performance.

Some assumptions have been made to explain the result that writing selfefficacy is not correlated with writing performance. It is assumed that there is over-estimation of one's self-efficacy. Lavelle and Zuercher in Khojasteh et al, 2016 claimed that learners with a selfefficacy significantly beyond their actual ability often overestimate their ability to complete tasks and this can lead to difficulties. However, learners with a selfefficacy significantly lower than their ability are unlikely to flourish and develop. It is possible that learners' self-efficacy in this study was either significantly beyond their actual ability or lower than their ability which led to this result.

Self-regulation is one of the factors that might directly affect writing compare to self-efficacy. According to Panadero et al in Oxford (2017), self-regulation is the control that learners have over their cognition, behavior, emotions, and motivation through the use of personal strategies to achieve the goals they have established. When learners register the highest sense of efficacy but low self-regulated learning, they would encounter problems and have difficulties to get their activities done. On the contrary, when learners have low self-efficacy, they are more likely to reflect on their inadequacies, thus detracting from problem solving effort (Bandura in Oxford 2017). In case of this study, self-regulated learning might play central role in writing since it is reflected on how far learners can direct themselves successfully through difficulties that accompany writing. In short, selfefficacy alone perhaps does not guarantee success in performing task.

\section{b) Correlation between Writing Risk Taking and Writing}

Focusing on the finding of correlation between risk taking and writing, the result of this study is in contrast with some previous researches (Suryani and Argawati, 2018 and Wang and Lin, 2015) that indicate that there is significant correlation between risk taking and speaking ability. Nevertheless, the finding of this study is in line with previous researches (Farahani and Hivechi, 2013 and Tavakoli and Ghoorchaei, 2009) that points to the fact that there is no correlation between risk taking and self-assessment of speaking ability and writing. On the contrary, these previous researches have not explained the finding why there is no correlation between the variables.

Concerning the finding of this study, there are some assumptions that might explain why there is no correlation between risk taking and writing. It is assumed that there is another factor which might directly influence writing. Framing problem is assumed as a factor that directly affects writing more than risk taking. According to Gass and Selinker in Cervantes (2013) framing problem is learner's evaluation of the potential outcome of a situation (framing a situation as a gain or loss). In this part, learners who took test in this study might perceive writing test as a supplementary activity which would not cause loss or failure to them. Thus, they remained as low risk takers since they would not experience loss. On the contrary, learners tended to have high risk taking when they foresee 
some kind of loss from the writing test. There is a possibility that learners evaluate writing test either as a gain or loss.

\section{CONCLUSION}

Based on the findings, there are two conclusions of this research: 1) there is not any significant correlation between writing self-efficacy and writing, 2) there is not any significant correlation between writing risk taking and writing. This research confirms that writing self-efficacy and risk taking do not predict success or performance in second language acquisition particularly in writing. Some variables are assumed to have direct relationship to writing than writing self-efficacy and risk taking such as overestimation, self-regulation, and framing a problem. It needs further investigation to check and verify these assumptions.

\section{Acknowledgement: None}

\section{Conflict of Interest: None}

\section{Source of Funding: None}

\section{REFERENCES}

1. Aragon, J., Claudia, E., Baires M., Dalia C., Rodriguez., and Gloria, S. 2013. An Analysis of the Writing Skill Difficulties of the English Composition 1 Students at the Foreign Language Department of the University of El Salvador. Unpublished Undergraduate Work. San Salvador: El Salvador Universty.

2. Bandura, A. 1997. Self-efficacy: The exercise of control. New York, NY: Freeman.

3. Brown, H. D. 2000. Principles of language learning and teaching. NY: AddisonWesley.

4. Caprara, G.V., Michele V., Guido A., Maria G., and Claudio B. 2011. The Contribution of Personality Traits and Self-Efficacy Beliefs to Academic Achievement: A Longitudinal Study. British Journal of Education Psychology, 81, 78-96.

5. Cervantes, I. M. 2013. The Role of RiskTaking Behavior in the Development of Speaking Skills in ESL Classrooms. Revista de Lenguas Modernas, 19, 2-10.
6. Chea, S. and Shumow, L. 2014. The Relationships among Writing Self- Efficacy, Writing Goal Orientation, and Writing Achievement. Journal of Language Education in Asia, Volume 5

7. Ely, C. M. 1986. An Analysis of Discomfort, Risktaking, Sociability, and Motivation in the L2 Classroom. Language Learning, 36 (1), 1-25.

8. Farahani, Ali A., and Hivechi, Z. 2013. The Relationship between Risk Taking and SelfAssessment of EFL Learners in Writing Ability. Mediterranean Journal of Humanities, Vol 3/1, 125-136.

9. Geramian, Seyedeh., Mashayekhi, S., and Moh, T. 2012. The relationship between Personality Traits of International Students and Academic Achievemnt. Social and Behavioral Science, Vol. 46.

10. Hashemnejad, F., Zoghi, M., and Amini, D. 2014. The Relationship between SelfEfficacy and Writing Performance across Genders. Theory and Practice in Language Studies, Vol. 4, No. 5.

11. Hatch, E. and Farhady, H. 1982. Research Design and Statistics for Applied Linguistics. London: Newbury House, Inc.

12. Hetthong, R. and Teo, A. Does Writing Self-Efficacy Correlate with and Predict Writing Performance? International Journal of Applied Linguistics and English Literature, Vol. 2 No. 1.

13. Khalifa, Mohammed, R. 2016. The Effectiveness of Using Think- Pair-Share Strategy on Developing Eleventh Graders' Writing Skills in Rafah Governmental Schools. Unpublished Master Thesis. Gaza: Al Azhar University.

14. Khojasteh, L, Shourkpour, N, and Afrasiabi, M. 2016. The Relationship between Writing Performance of Iranian EFL Students. International Journal of Applied Linguistics and English Literature, Vol. 5 No. 4

15. Latif, M. A. 2007. The factors accounting for the Egyptian EFL university students' negative writing affect. Essex Graduate Student Papers in Language \& Linguistics, 9, 57-82.

16. Lee, Y., and Reid, M. 2016. The Role of Self-efficacy in Reading Achievement of Young Children in Urban Schools. Child Adolesc Soc Work J, 33:79-89

17. Leeming, P. 2017. A Longitudinal Investigation into English Speaking SelfEfficacy in a Japanese Language Classroom. 
Leeming Asian-Pacific Journal of Second and Foreign Language Education, 2(12)

18. Luft, S. D. 2007. Language classroom risktaking behavior in a performed culturebased program. Unpublished Master Thesis. Columbus: Ohio State University

19. Ni, Hui. 2012. The Effect of Affective Factors in SLA and Pedagogical Implications. Theory and Practice in Language Studies, Vol. 2, No. 7.

20. Nunan, D. 1991. Language Teaching Methodology. London: Prentic Hall International.

21. Oxford, R. 2017. Teaching and Researching Language learning strategies: SelfRegulation in Context ( $2^{\text {nd }}$ edition). New York and London: Routledge.

22. Pajares, F., \& Valiante, G. 1997. Influence of self-efficacy on elementary students' writing. Journal of Educational Research, 90, 353-360.

23. Rahimi, A., and Abedini, A. 2009. The Interface between EFL learners' SelfEfficacy Concerning Listening Comprehension and Listening Proficiency. Novitas - Royal, Vol.3(1).

24. Raimes, A. 1983. Techniques in Teaching Writing. New York: Oxford UP Print.

25. Richards, J. C. \& Schmidt, R. 2002. Longman Dictionary of Language Teaching and Applied Linguistics. (3rd ed.). Essex: Pearson Education Limited.

26. Samaranayake, S. W. 2015. Relationship between Additional Language Learning and
Risk Taking. Int.J.Eng.Lang.Lit \& Trans. Studies, Vol 2 Issue (3).

27. Suryani, L. \& Argawati, Ningtyas, O. 2018. Risk-Taking and Students' Speaking Ability: Do They Correlate? ELTIN Journal, Vol.6/1.

28. Tavakoli, M. \& Ghoorchaei, B. 2009. On the Relationship between Risk taking and Self-assessment of Speaking Ability: A Case of Freshman EFL Learners. The Journal of Asia TEFL, Vol. 6, No.1.

29. Wang, Y., and Lin, Y. 2015. A Study on Correlation of Risk-Taking and the Oral Production of English Majors in China. English Language Teaching; Vol. 8, No. 10.

30. Youngjoo, B. 1999. Factors Affecting Korean Students' Risk-Taking Behavior in EFL Classroom. Unpublished Doctoral Thesis. Columbus: Ohio State University.

31. Yusuf, M. 2011 The Impact of Selfefficacy, Achievement Motivation, SelfRegulated Learning Strategies on Students' Academic Achievement. Procedia Social and Behavioral Sciences, Vol. 15.

32. Zafar, S, and Meenakshi, K. 2012. Review of PhD Theses on the Role of Personality in SLA. English Language and Literature Studies, Vol. 2, No. 1.

How to cite this article: Sari FPN. An investigation of learners' writing self-efficacy and risk taking in writing. International Journal of Research and Review. 2021; 8(9): 92-98. DOI: https://doi.org/10.52403/ijrr.20210913 